\title{
A research study to identify facilitators and barriers to outcome measure implementation
}

\author{
Maria Dunckley, Fiona Aspinal, Julia M Addington-Hall, Rhidian Hughes, Irene J Higginson
}

\section{Abstract}

Aim To identify facilitators and barriers to implementing outcome measures.

Methods An action-research approach within a hospice and nursing home was used. Staff took part in semistructured interviews pre- and post-implementation of the Palliative Care Outcome Scale (POS), completed diaries and participated in monthly meetings.

Findings Qualitative content analysis identified barriers to implementation including: a top-down decision-making approach; outcome measures perceived as time-consuming to use; limited resources for data analysis; and a lack of knowledge of the importance of outcome measures. Facilitators to successful implementation include: involving all staff in decisions about implementation; and using a measure that can be adapted to organization needs and clinical practice. The benefits of using the measure are rapidly noticeable.

Conclusions Given the need to evaluate services and the role outcome measures can have within clinical governance, this article indicates methods by which measures may be more successfully implemented.
\end{abstract}

Maria Dunckley is

Researcher, Interdisciplinary

Research Centre in Health,

School of Health and Social

Sciences, Coventry

University, Coventry,

Fiona Aspinal is Researcher,

Department of Politics,

University of York,

Heslington, York,

Julia M Addington-Hall

is Professor of End of Life

Care, School of Nursing and

Midwifery, University of

Southampton, Highfield,

Southampton,

Rhidian Hughes is

Honorary Visiting Fellow,

Centre for Health and Social

Care, School of Policy

Studies, University of

Bristol, Bristol, and

Irene J Higginson is

Professor of Palliative Care,

Department of Palliative

Care and Policy, Guy's,

King's and St Thomas'.

School of Medicine, King's

College London, Cutcombe

Road, London

Correspondence to:

Maria Dunckley

Email:

M.Dunckley@Coventry

.ac.uk
$\mathbf{T}$ The Department of Health's (DoH, 2000) NHS Plan recommends that service evaluation become a regular and integral component of clinical practice. Professional bodies, such as the General Medical Council (GMC) and the Royal College of Nursing (RCN), also emphasize clinical governance as a vital component of healthcare practice (GMC, 2001; RCN, 2003).

Clinical audit is one important component of service evaluation. It is a cyclical process whereby quality of care is monitored against wider goals, outcomes or standards and results are fed back to effect change (National Institute for Clinical Excellence (NICE), 2002). Clinical audit is important because it provides an evidence base for practice and for service development by demonstrating the effectiveness of clinical interventions, and services more generally. Furthermore, in a resource-limited health service, where it is essential that resources are used in an effective and efficient way, audit can ensure resources are directed to care that works.

Outcome measures have been developed to facilitate clinical practice and are widely used in audit and research to enable outcomes to be measured systematically. Outcome measures usually comprise questionnaires or checklists completed by service users or health professionals. They assess effectiveness and outcomes of treatments and interventions (Bowling, 1997a; Salek et al, 2002) and help guide patient care. For example, by assessing the patient's symptom control and quality of life, and providing evidence to improve the quality of services (Hearn and Higginson, 1997). As healthcare organizations conduct clinical audits and further develop individualized care plans, for example, as outlined in The NHS Plan (DoH, 2000), outcome measures are becoming established and integral to clinical practice.

There is literature on the development and testing of outcome measures (Bowling, $1997 \mathrm{~b})$. While investigation into issues associated with the introduction of clinical practice guidelines has begun (Sheldon et al, 2004), successful implementation of outcome measures has received less attention (Hughes et al, 2004b). The Project to Improve Management of Terminal Illness (PROMOTE) aimed to develop mechanisms for monitoring regularly the quality of palliative care services (Hughes et al, 2001, 2004a). One component of the study explored the feasibility of implementing and using an outcome scale developed specifically for palliative care - the Palliative Care Outcome Scale (POS) (Aspinal et al, 2002) - in non-specialist palliative care settings (Hughes et al, 2004b).

To further understand the barriers to outcome measure implementation and to identify and facilitate methods of overcoming these hurdles, an action research study was undertaken in the UK. Two contrasting settings providing care for 
people with palliative care needs, and who had expressed an interest in undertaking palliative care research, were approached to take part. A specialist hospice inpatient unit and a nursing home providing care for people with neurological illness, both in the greater London area, were used as comparative in-depth case studies.

\section{Method}

An action-research approach was used to explore implementation of the POS. The POS is a 10 -item questionnaire covering: physical and psychological symptoms; and spiritual, practical and emotional concerns. It has been used successfully in a variety of settings. There are two versions of the questionnaire, one for patients to complete, and the other for staff. It is a flexible tool, the usage of which can be determined by the needs of local services (Hearn and Higginson, 1999; Aspinal et al, 2002).

\section{Action research}

Action research is a valuable approach for assessing and improving health service provision (Hart and Bond, 1995; Meyer, 2000). It identifies and defines needs and problems while simultaneously devising methods of meeting those needs and redressing problems around service provision. Action research promotes a participatory, self-reflective and critical approach to data collection, where participants actively work in collaboration with researchers throughout the research process. Change is led by people within the organizations and all participants are enabled to assist in the evolution and improvement of services. At a local level, such an approach can help to minimize the research-practice gap (Scott, 1999).

As part of this study, the POS was implemented as a routine part of clinical care within the nursing home and the hospice inpatient unit, neither of which had used the

\section{Table I. Participants agreeing to take part in each study} component

\begin{tabular}{lccl} 
Study component & Hospice & Nursing home & Total \\
\hline ARC & 8 & 7 & 15 \\
\hline Interviews & 5 & 10 & 15 \\
\hline Diaries & 3 & 9 & 12 \\
\hline Total & 16 & 26 & 42
\end{tabular}

Some participants took part in more than one study component; $\mathrm{ARC}=$ action research collaborative
POS before this study. As part of the study, staff at the two organizations were invited to participate in any or all of the three research components: action research collaborative (ARC) meetings with the research staff; interviews; or diary completion.

\section{Data collection}

\section{$A R C$}

This consisted of regular monthly meetings with the research team and organization staff to establish implementation of the POS, monitor progress, discuss emerging issues, amend implementation plans, where necessary, and develop strategies for change.

\section{Interviews}

Staff took part in two semistructured interviews: one before and another after POS implementation. Interviews asked participants about their experiences of using the POS and focused on difficulties encountered and benefits obtained.

\section{Diaries}

Staff completed a diary on an 'as-andwhen' basis, recording their experiences of implementation.

Both sites used the POS for 10 weeks. During that time the research team made frequent site visits to aid understanding of the implementation process. Multicentre Research Ethics Committee approval was given for this study.

\section{Analysis}

The data from diaries, interviews and ARC meetings (including field notes and minutes of meetings) were analysed. Codes were apportioned to text and these codes were grouped thematically by content. The findings were integrated by identifying broad themes common to each data set.

\section{Participants}

\section{Findings}

Recruitment packs were given to all 28 permanent nursing home staff and to 23 clinical hospice staff. Participants agreeing to take part in each component of the study are given in Table 1 .

Eight registered general nurses (RGNs), one doctor and six healthcare assistants (HCAs) took part in pre-implementation interviews. Interviews ranged from 10 to 35 minutes, taking 20 minutes on average to complete. Participants from three nursing homes and one hospice declined to take part in the second interview and did not give a reason for their 
decision. Five RGNs and seven HCAs completed a diary. Many nursing home diary participants were unsure of how to complete the diaries or what was expected of them. Further explanation did not alleviate this confusion and consequently five staff withdrew. Four RGNs, two doctors, one HCA and one administration/support staff attended hospice ARC meetings. Two managers (both also RGNs), one doctor (also a trustee), two RGNs and two HCAs attended nursing home ARC meetings.

\section{Barriers and facilitators to implementation}

Barriers and facilitators to implementation are summarized in Box 1. As participants consented to the study they were assigned a random identification number to maintain anonymity. Quotes from interview transcripts are included for illustrative purposes where appropriate; ' $N$ ' indicates a member of staff from the nursing home and ' $\mathrm{H}$ ' a member of staff from the hospice.

\section{Box I. Barriers and facilitators to outcome measure implementation}

\begin{tabular}{|c|c|}
\hline Barriers & Facilitators \\
\hline $\begin{array}{l}\text { Top-down approach } \\
\text { to decision making }\end{array}$ & $\begin{array}{l}\text { - Cascade management style is adopted } \\
\text { - Coordinator is identified to undertake overall } \\
\text { responsibility for implementation } \\
\text { - All staff included in decision-making processes }\end{array}$ \\
\hline $\begin{array}{l}\text { Implementation and use } \\
\text { of the measure } \\
\text { is time-consuming }\end{array}$ & $\begin{array}{l}\text { - Senior staff acknowledge the time needed } \\
\text { to implement and use outcome measures } \\
\text { - Every member of the team who should } \\
\text { be completing the outcome measures does so } \\
\text { - Existing structures of working utilized, e.g. team } \\
\text { nursing/primary nursing } \\
\text { - A measure that is easy and quick to use is chosen } \\
\text { - Outcome measures are not used too frequently } \\
\text { - Burden of measure completion on patient/ } \\
\text { residents is considered }\end{array}$ \\
\hline $\begin{array}{l}\text { Limited access } \\
\text { to resources for data } \\
\text { analysis }\end{array}$ & $\begin{array}{l}\text { - Measures that can be analysed using existing } \\
\text { resources are used } \\
\text { - Advice is obtained on how to analyse the data } \\
\text { - Link with a research/audit group is established }\end{array}$ \\
\hline $\begin{array}{l}\text { Perception that the } \\
\text { measure is not relevant } \\
\text { to practice, the } \\
\text { organization or the } \\
\text { client group }\end{array}$ & $\begin{array}{l}\text { - Data has to be seen to be used } \\
\text { - Benefits of using outcome measures are easily } \\
\text { and rapidly noticeable } \\
\text { - Measure asks about issues that are relevant } \\
\text { to clinical care } \\
\text { - Relevance to the organization, staff and clients, } \\
\text { are improved by use of measures that can be adapted } \\
\text { to local circumstances }\end{array}$ \\
\hline $\begin{array}{l}\text { Lack of knowledge and } \\
\text { understanding about } \\
\text { the importance } \\
\text { of outcome measures }\end{array}$ & $\begin{array}{l}\text { - Complement the introduction of outcome } \\
\text { measures with staff training about the specific } \\
\text { measure and wider relevant issues of audit } \\
\text { and research } \\
\text { - Staff are encouraged to view outcome measures } \\
\text { as an integral component of clinical care }\end{array}$ \\
\hline
\end{tabular}

Top-down approaches to decision making One important influence on implementation and acceptance of the outcome measure was the adoption of a 'cascade' management style within the nursing home. Here, senior staff conducted the first assessment and then 'cascaded' the knowledge to junior staff. Although this appears to be a top-down management approach, it differs from truly hierarchical approaches as junior staff, once using the tool within their key-work teams, were entrusted with using the POS and encouraged to challenge and question its use and develop its role within the organization. Within 4 weeks of being introduced it was reported at the ARC that the POS had become a routine part of care.

In the hospice a much more hierarchical management style was evident. For example, this was observed when recruiting for ARC membership. In the nursing home all staff were invited to take part; whereas, in the hospice, senior staff selected staff to participate. The management style was also clear in the way both the research and POS introduction were managed. As one nurse said:

'I think there is a certain element that you will be doing it, and that suddenly we were doing it and nobody really talked about that' (Nurse 20; H).

An ARC member explained that a hierarchical management style was necessary because many hospice staff worked parttime. As such, it was reported that unless this management style was employed it would be difficult to implement any audit tool. One of the nurses interviewed stated:

'I mean, I don't think it would have arisen out of us saying: "Hey. We need an audit tool"' (Nurse $06 ; H$ ).

Despite the hierarchical approach to management, nurses' and HCAs' views were collected and presented as discussion points at ARC meetings. However, in the hospice, junior staffs' suggestions were less readily accepted and less likely to inform POS use; staff were informed of decisions rather than encouraged to participate in them.

\section{Time consuming}

Before POS implementation, participants were concerned about the time needed to learn and administer a new measure:

'Time. You know, getting the time to do it' (Nurse 06; $N$ ). 


'Healtbcare
assistants (HCAs)
viewed the
Palliative Care
Outcome
Scale (POS)
primarily as
a communication
tool that
promoted
relationships
with their clients.'

'They're [outcome measures] timeconsuming, and you have to learn to do them...' (Nurse 12; H).

However, post-implementation, nursing home staff noted that incorporating the POS into routine practice had been easier than anticipated. Staff found the POS was easy to administer and, once familiar with it, was quick to use and soon part of the working routine:

'Well, initially, it took a bit longer but, as they got used to the questions and the questionnaire and the ways they had to fill them in, then it took even less of their time' (Nurse 07; $N$ ).

'I think, initially, at the beginning, it was difficult to try and work out when exactly everybody could fit it in. But I think, as time went on, we'd say: "Right, we've got 10 minutes, we're going to do POS," and things like that' (Nurse 06; $N$ ).

Hospice staff did not reflect this familiarization with the POS and its incorporation into routine care, instead noting that outcome measure completion has to compete for priority with clinical-care tasks, which, given the more acute setting, are often unpredictable:

'I think it's quite difficult all round. I think it's an effort that people have to make; it's something that they have to prioritize' (Nurse 12; H).

'....also things like, when you're busy, POS like all pieces of paperwork, is always bottom' (Nurse 06; H).

Implementing outcome measures also required an acknowledgment from senior staff of the time needed for staff to familiarize themselves with the measure and administer it. Nursing home ARC minutes showed an awareness from managers that staff were unfamiliar with the POS and would, therefore, need extra time to administer it at first. The researchers provided training sessions on the POS and its use, which the nursing home paid staff to attend. Such explicit considerations of learning and familiarization were not identified within hospice ARC meetings, although this may be owing to the hospice staffs' pre-existing knowledge and routine use of other similar outcome measures.

The lack of a formal team nursing approach within the hospice meant there was no established situation or time that
POS administration could be incorporated into. Subsequently, not all staff administered the POS and the task fell to a few staff; therefore, increasing their workloads. This could not happen within the nursing home as the key-worker system meant all HCAs were responsible for POS completion with team leaders overseeing the process.

Not administering the POS too frequently was instrumental to implementation success and acceptance. Within the nursing home, residents were more stable and administration every week was considered too frequent by RGNs. It is interesting to note, however, that HCAs completing diaries, by contrast, considered weekly POS use to be most appropriate. However, HCAs viewed the POS primarily as a communication tool that promoted relationships with their clients and for which weekly administration was ideal. Important to RGNs were the benefits of POS use to clinical care, for which a flexible approach to administration was more relevant to the typically stable client population:

'Fortnightly or monthly, that would do. So if we do it on a fortnightly basis and, perhaps, have room for those that might have acute conditions' (Nurse 07; N).

The hospice ARC debated the frequency of POS administration at most meetings, with agreement between ARC members and inpatient unit staff difficult to achieve. Staff administering the POS felt the assessments every 3 days placed an unacceptable burden on patients, some of who lost track of time and believed they were being asked to complete the POS every day. Additionally, staff were reluctant to ask patients to consider the issues contained within the POS, feeling this an unacceptable intrusion:

'I just struggle with it as a tool us being able to use it as often as it needs to be used in the unit that, at times, is very understaffed and is just... so acute' (Nurse 20; $H$ ).

'One of the things I am worried about is the feeling that patients are doing it too often. Patients cope very well with denial. And even if they're forced to look at a situation, they can look at it, but then they can re-group it in their mind. I'm not averse to this tool but, I think, sometimes, having to face it every 3 days, I think is hard' (Nurse 12; H).

The impact of outcome measure completion on patients and residents was a 


'Field notes
from the nursing
bome reflect
an overwbelming
sense of the
benefit of using
the Palliative
Care Outcome
Scale (POS)
in ensuring
that all staff
felt their
contribution
to resident care
was valuable.'

concern for staff at both organizations. In general, patients and residents had few difficulties completing the POS. Nursing home staff reported several residents enjoyed it, although it was comparatively common in both organizations for a patient or resident to complete the form a couple of times and decline thereafter.

\section{Limited access to resources for data analysis}

The lack of resources to analyse outcomemeasure data was discussed in depth in later ARC meetings. Summary scores were kept at the nurse's station so that they were available for staff to review patients on an individual basis; however, the hospice also wanted data to be used to predict patient outcomes. This required more statistical analysis than was available to both settings.

Perception that the measure is not relevant to practice, the organization or the client group

One factor that helps staff accept outcome measures is to ensure that the resulting data will be used:

'...just doing work for the sake of it. Getting data that you do nothing with...It's just a waste of time' (Nurse 06; H).

Staff at the nursing home did not identify this as an explicit concern. However, during ARC meetings and follow-up interviews it became apparent that senior staff had preempted these concerns by discussing POS scores at weekly team meetings so enabling all staff to see the importance and relevance of the data they were collecting. POS scores at the nursing home were also used to inform GP consultations:

'And it's obviously something that you could actually say to the GP: "The carers have found this", you know, "I've found that"' (Nurse 03; N).

Pro-active promotion of the POS to inform and guide clinical care can help explain the high level of acceptance of the measure within the nursing home. Direct clinical benefits of using the POS were less apparent to hospice staff, probably owing to the complex clinical needs of their patients that the POS is not sensitive enough to detect (Hughes et al, 2004c). Hospice staff noted that if the POS scores were routinely discussed clinical benefits may be apparent:

'It would be a great tool to go through one a week or once every 5 days, and review all the care plans' (Nurse 06; H).
However, the hospice staff noted other benefits to using the POS, including as a communication aid and as a valuable tool to promote patient-centred care:

'Sometimes communication is the last thing that you think about and it should be the first thing you think about, because you find out so much more' (Healthcare Assistant 04; H).

'It is important that we give patients opportunities to express how they feel' (Nurse 12; $H$ ).

Similarly, the nursing home staff also reported numerous and far-reaching benefits from POS use:

'The benefits [of using POS] are multifactorial and you don't get them just from the training aspect, you get them from the clinical aspects, we get them from the type of psychological aspects of the residents, and even the carers themselves' (Nurse 07; N).

Field notes from the nursing home reflect an overwhelming sense of the benefit of using the POS in ensuring that all staff felt their contribution to resident care was valuable. At the end of the 10-week POS use period, the researchers felt a great change in the outlook of HCAs towards their role within the nursing home. Whereas senior staff had always intimated to the research team that HCAs were vital to resident care, the POS provided an observable method by which HCAs themselves could see the importance of their work and their integral role within the care team:

'They feel they fit in, they feel important, they are a member of the team... and it helps them to realize that whatever you do is important' (Nurse 07; N).

Communication benefits of using the POS were also quickly apparent to nursing home staff. The POS helped legitimize time spent with residents:

'Actually, that - the POS - actually helps us to be able to have the one-to-one talk with the client actually, which is very, very good. We were able to sit and chat with the client' (Nurse 04; N).

'...it was nice to sit down and sort of ask them...normally you have to rush around. You know, if you've got a list of things you have to do, it's not easy to find time to actually sit down with them. You can chat to them while you're doing 
'...a critical

and unresolved

barrier was

the top-down

approach

to decision

making, which

bindered

the use of the

Palliative Care

Outcome Scale

(POS) witbin

the bospice

setting.' things, but to actually sit down and do it, just once a week, you know' (Nurse 06; $N$ ).

The POS did not contain the level of detail required by hospice staff to guide clinical care. However, its use as a general outcome measure and as an audit tool was felt by both organizations who perceived the questions within it were useful to their provision of care. Staff at both organizations commented positively on the inclusion of psychosocial aspects:

'When I read it over, I thought it was... an overall thing for the resident really... So I did like the psychological side of it, because I think, as nurses - especially in a general place - you are thinking more physical. So I was pleased that, you know, that that side was in' (Nurse 01; $N$ ).

'It's often very hard to score as a priority some of the psychosocial things, and this does give us a good way of monitoring that side of things - which I think is probably what we're least good at' (Doctor 10; H).

Lastly, the hospice and nursing home both considered the POS a benefit to professional development. Hospice staff referred to reflective practice, the ability of the POS to challenge staffs' perception of patients' problems. Senior nursing home staff discussed how the POS was educational in helping to provide a framework for observations of residents, particularly for inexperienced staff:

'You know, I've constantly scored high [indicating more of a problem] when I've done it, because if I had their problems, I'd be wretched. But then to have patients with really awful problems score themselves low, you know, that is a classic. Because it just says that my perception is different to theirs' (Nurse 12; H).

' $I$ have a strong belief in it being an educational tool because it did help the carers here I think' (Nurse 04; N).

Lack of knowledge and understanding about the importance of outcome measures Use of the POS for audit was not well known by the staff who administered the measure in either organization. The nursing home manager (also an RGN) and sisters at both organizations who were interviewed were aware of the importance of documenting good care provision and perceived the POS as one method to achieve this provision:

'If you're going to audit and things like that...when the registration inspectors come round, they'll see that you are looking after them [residents] and caring for [them]...so it's going to be a positive thing in the write up that they do of you' (Nurse 03; N).

'I mean, we are an independent charity; we do need to prove to the PCT what we're doing. So it is a tool to prove the level of service people get, to get funding' (Nurse 12; H).

\section{Discussion}

Barriers to outcome measure implementation have received little attention despite their use becoming an integral part of clinical care. However, some work on the general views of audit held by palliative care service managers, audit leads and junior doctors has been published and supports the findings from our study (Cheater and Keane, 1998; Nettleton and Ireland, 2000; Charlton et al, 2002). Our study contributes to current understanding by using an action-research approach to allow organizations to raise and adapt to the obstacles they faced.

Both the hospice and nursing home overcame many barriers to implementing the POS. However, a critical and unresolved barrier was the top-down approach to decision making, which hindered the use of the POS within the hospice setting. This finding supports previous work by Cooper and Hewison (2002) who identified 'good relationships with management...as crucial to success'. A good relationship with managers involves management having both an awareness of the extra time needed to implement new outcome measures and providing the appropriate resources and practical support to use the measures and carry out data analysis (Cheater and Keane, 1998).

The potential for outcome measure implementation to be time consuming was a concern to the participants in our study and others (Cheater and Keane, 1998; Black and Thompson, 1999; Nettleton and Ireland, 2000; Charlton et al, 2002; Hughes et al, 2003). We can also suggest that the initial phase of implementation is the most time consuming and once measures are integrated into routine care their use may not add an unduly large burden on workloads so long as the measure itself is easy to administer. 
Potential for patient burden was highlighted as a barrier to implementation of the POS in this study, and complements existing research (Massaro and Mcmillan 2000; Charlton et al, 2002). Palliative care patients can be very unwell and the potential for health professionals to act as a proxy is beneficial. The fact that the POS could be modified to better reflect the specific requirements of each organization was valued, as also indicated in earlier work (Hughes et al, 2004b). Here the benefits of implementing the measure had to be easily identifiable for staff to feel its continued use was worthwhile in improving care. The timely feedback of results is, therefore, very important (Cooper and Hewison, 2002).

It is also important to recognize professionals' lack of knowledge of audit. Black and Thompson (1993) found physicians generally understand the need for audit, although Nettleton and Ireland (2000) report that junior doctors had little understanding of the process itself. This suggests that facilitating outcome-measure implementation involves incorporating training not only on how to use the measure but also of wider audit and quality issues (James and Kehoe, 1999; Hughes et al, 2004b, Hughes et al, 2004c). Training may also help health professionals identify how audit may be useful in clinical practice, rather than a meaningless exercise, as some studies suggest (Nettleton and Ireland, 2000).

\section{Conclusion}

Little is known about professionals' views of audit and the ways individuals and organizations adapt when implementing outcome measures (Hughes et al, 2003; Nightingale et al, 2003). Further research on a larger scale is necessary to explore the ways in which palliative care settings adapt to monitoring demands and change. In particular, there needs to be an investigation of specific issues within other areas of health care.

Given the continuing policy drive towards service evaluation and clinical audit, methods to promote the successful and straightforward incorporation of outcome measures into routine clinical practice are required. Although further research is needed to investigate the generalizability of these findings to other settings, patient groups and measures, these findings provide guidance to those seeking to ensure that information on patient outcomes is at the heart of service improvements in and beyond the NHS. IIPN
The Project to Improve Management of Terminal Illness (PROMOTE) team wish to thank the staff at the nursing home and hospice for their involvement in the research. We are also grateful to the project advisory group for their support throughout this study. This study is part of PRO MOTE which is funded by The Community Fund.

Aspinal F, Hughes R, Higginson IJ, Drescher U, Thompson M (2002) A User's Guide to the Palliative Care Outcome Scale. Palliative Care and Policy Publications, London

Black N, Thompson E (1993) Obstacles to medical audit: British doctors speak. Soc Sci Med 36: 849-56

Bowling A (1997a) Research Methods in Health: Investigating Health and Health Services. Open University Press, Buckingham

Bowling A (1997b) Measuring Health: A Review of Quality-of-Life Measurement Scales. 2nd edn. Open University Press, Buckingham

Charlton R, Smith G, White D, Austin C, Pitts M (2002) Audit tools for palliative care services: identification of neglected aspects of care. Am J Hosp Palliat Care 19:397-402

Cheater FM, Keane M (1998) Nurses' participation in audit: a regional study. Quality in Health Care 7:27-36

Cooper J, Hewison A (2002) Implementing audit in palliative care: an action research approach. $J A d v$ Nurs 39: 360-9

DoH (2000) The NHS plan. Stationery Office, London GMC (2001) Good Medical Practice. GMC, London

Hart E, Bond M (1995) Action Research for Health and Social Care: A Guide to Practice. Open University Press, Buckingham

Hearn J, Higginson IJ (1997) Outcome measures in palliative care for advanced cancer patients: a review. J Public Health Med 19: 193-9

Hearn J, Higginson IJ (1999) Development and validation of a core outcome measure for palliative care: palliative care outcome scale. Quality in Health Care 8: 219-27

Hughes R, Higginson IJ, Addington-Hall J, Aspinal F, Thompson M, Dunckley M (2001) Project to impROve Management Of Terminal illnEss (PROMOTE). J Interprof Care 15: 398-9

Hughes R, Aspinal F, Addington-Hall J, Chidgey J, Drescher U, Dunckley M, Higginson IJ (2003) Professionals' views and experiences of using outcome measures in palliative care. Int J Palliat Nurs 9: 234-8

Hughes R, Addington-Hall JM, Aspinal F, Dunckley M, Higginson IJ, (2004a) Developing methods to improve the quality of end-of-life care. J Interprof Care 18: 200-1

Hughes R, Aspinal F, Addington-Hall JM, Dunckley M, Faull C, Higginson I (2004b) It just didn't work: the realities of quality assessment in the English health care context. Int J Nurs Stud 41: 705-12

Hughes R, Aspinal F, Higginson I, Addington-Hall JM, Dunckley M, Faull C, Sinha A (2004c) Assessing palliative care outcomes for people with motor-neurone disease living at home. Int J Palliat Nurs 10: 449-53

James M, Kehoe R (1999) Using the health of the nation outcome scales in clinical practice. Psychiatr Bull R Coll Psychiatr 23: 536-8

Massaro T, Mcmillan SC (2000) Instruments for assessing quality of life in palliative care settings. Int J Palliat Nurs 6: 429-33

Meyer J (2000) Using qualitative methods in healthrelated action research. $B M J$ 320: 178-81

Nettleton J, Ireland A (2000) Junior doctors' views on clinical audit - has anything changed? Int J Health Care Qual Assur 13: 245-53

NICE (2002) Principles for Best Practice in Clinical Audit. Radcliffe Medical Press, Abingdon

Nightingale E, Kristjanson LJ, Toye C (2003) Evaluating the Navigate Care Model: clinical palliative care pathways based on anticipated care outcomes. Int J Palliat Nurs 9: 299-307

RCN (2003) Clinical Governance: An RCN Resource Guide. RCN, London

Salek S, Pratheepawanit N, Finlay I, Luscombe D, (2002) The use of quality-of-life instruments in palliative care. European Journal of Palliative Care 9: 52-6

Scott D (1999) The research-policy gap. Journal of Education Policy 14: 317-37

Sheldon TA, Cullum N, Dawson D et al (2004) What's the evidence that NICE guidance has been implemented? Results from a national evaluation using time series analysis, audit of patients' notes, and interviews. BMJ 329: 999-1003 